\title{
What Is Construed as Relevant Knowledge in Physics Teaching? Similarities and Differences in How Knowledge and Power Are Staged in Three Lower Secondary Classrooms
}

\author{
Malena Lidar $^{1}$ (D) Anna T. Danielsson ${ }^{1,2} \cdot$ Maria Berge $^{3}$
}

Published online: 2 May 2018

(C) Springer Nature B.V. 2018

\begin{abstract}
The content that is privileged in teaching has consequences for what the students are given the opportunity to learn and can thus be regarded as an aspect of power. We analyse power aspects in the teaching of physics by identifying actions that guide or direct other people's actions, and then analyse similarities and differences in different classrooms in terms of how governance is staged and what potential consequences this can have. The analyses are made on data from classroom activities, documented through video recordings and field notes, in three lower secondary schools in Y8 and Y9, respectively. At first glance, teachers from all three schools adhere to a traditional interpretation of a physics curriculum. But a more in-depth analysis shows that the students in the different classrooms are given quite dissimilar opportunities to participate in teaching and create relationships with the content. What appears to be a desirable way of acting offers different conditions for meaning-making. In an increasingly individualised society where people are expected to be active, reflective and make choices for their own personal good, the students in these three classrooms are offered very different conditions to practice and learn to take part in knowledge-making, connect physics content to their everyday life and exercise informed citizenship.
\end{abstract}

Keywords Physics teaching $\cdot$ Power $\cdot$ Knowledge $\cdot$ Governance

Malena Lidar

malena.lidar@edu.uu.se

Anna T. Danielsson

anna.danielsson@edu.uu.se

1 Department of Education, Uppsala University, Uppsala, Sweden

2 School of Education and Professional Studies, King's College London, London, UK

3 Department of Science and Mathematics Education, Umeå University, Umeå, Sweden 


\section{Introduction}

On a general level, there are different purposes for studying science in school. One purpose is that the students are to be introduced to the basic knowledge and skills of the science disciplines. Thus, teaching is designed to prepare students for further studies in the subject. Another purpose is that the students are to learn how to use science knowledge and skills in their everyday life. This purpose is sometimes extended to informed citizenship, where students ought to be able to make informed decisions on social, political and moral issues. From this perspective, education is conceived as preparing students for participation in a democratic and knowledge-intensive society, where citizens are expected to be informed about and have insight into crucial global socioscientific issues, such as energy supply, resource management and climate change (Fensham 1988; Roberts 2007).

The starting point for the study presented here is that when someone participates in teaching and learning activities, for example in science education, they learn much more than the content knowledge being taught. Along with learning science, they learn about the purposes of science education, in other words, the norms and values of the science classroom and what counts as relevant knowledge in the science classroom (Östman 1998). The categorisation of 'curriculum emphases' can be used to highlight such different purposes as related to the content choices that are possible in science teaching. Curriculum emphases describe an epistemological content dimension that involves knowledge about scientific knowledge and purposes in scientific activity (Roberts 1982, 2007). The teaching process, thus, includes students learning the implicit or explicit norms for what are considered to be proper, normal and reasonable ways to act and behave in a school science context. However, a challenge is that the norms imply a particular way of being a student, which is easily achievable for some while for others it could be almost impossible. Physics in particular has been shown to be difficult for many students to identify with (Archer et al. 2015; Francis et al. 2016; Bøe and Henriksen 2013) and despite the fact that students express an interest in science and science learning, they do not consider science to be a possible career (Archer et al. 2012).

In the teaching of science, a teacher always has to make choices about what purposes to pursue, what content to include and how to present it to the students. Wertsch (1991) argues that the process of privileging a certain content in teaching may be considered an aspect of power and as such is an explanation as to why students will learn certain things and not others. A Foucauldian perspective on power calls for that knowledge and power are understood as inextricably related (Foucault 1982/2002). As such, this perspective provides a powerful and novel way of investigating what happens when specific knowledge or purposes are privileged in classroom practice. The privileging of specific knowledge and purposes communicates what aspects are to be noted or are considered as desirable. Students could thus, for example, learn that science always has the best answer for making decisions in society and that decisions thereby ought to be made by scientific experts, or they could learn that everybody could be part of making responsible decisions, given that they have achieved a certain degree of scientific literacy. Considering that science teaching thus has profound consequences for shaping students' future possibilities to act in society, it is important to consider how different science teaching practices and content may affect the competences students learn when it comes to dealing with the discipline (Mogensen and Schnack 2010). We want to elucidate how the content and actions in a teaching practice favour particular ways of acting and being. This is the key to understanding how certain actions construe the possibilities and limitations for students to think about science, the world, themselves and other people in specific ways. The 
investigation here is conducted by analysing teaching activities in physics education in three Swedish classrooms. The three classrooms have different social, economic and cultural conditions for teaching. As such, it is possible that different teaching and learning practices will unfold across the different classrooms. In essence, what we investigate is how different approaches to teaching give possibilities and limitations for student meaning-making and action.

In exploring how power operates in the teaching of physics, we take a transactional approach to classroom practices, understanding them, with respect to both content and form, as reciprocally constituted by teachers and students (Dewey and Bentley 1949/1991; Östman and Öhman 2010). Dewey and Bentley (1949/1991) describe how both human beings, and our worlds, are created through the encounters we experience. Consequently, neither we, the things we create, nature nor social phenomena have any meaning in themselves, but are construed differently depending on the encounters or events through which they occur. To study meaning-making in this perspective thus involves taking the encounters between individuals (with their experiences and sociocultural resources) and the environment into account. Individuals and context are viewed as a whole where one does not precede the other (Dewey and Bentley 1949/1991). The relation between actions and their consequences is thus not causal and linear, but reciprocal. Hence, the meaning in a situation is constituted in interplay between the participants in the situation, which allows power relations to be comprehended as the 'action upon the actions of others' (Foucault 1982/2002, p. 343; cf. Öhman 2010). The premise that actions always influence other actions and that this leads to further actions taking particular directions is central to Foucault's perspective on power. That is, in relation to a teacher's question, several student responses may be possible, but not just any response. In Foucault's (1982/2002) terminology, an action structures the field of possible actions of others. Power, then, is both about possibilities and limitations where some actions are made possible and desirable and others are not. We use the Foucauldian idea of power as action-on-action, and as such something that is acted out in practices of people in everyday life. Knowledge is intimately bound up with power in this process, as any knowledge claim is simultaneously constitutive of power relations that make this particular knowledge considered legitimate and possible (Foucault 1977).

Quennerstedt (2008) has argued that this Foucauldian conceptualisation of knowledge and power is well aligned with a transactional approach and makes it possible to strengthen the consideration of power relations within this approach. Further, Barker and Quennerstedt (2016) argue that in attending to how teachers and students produce meanings in their local classroom setting, it is also important to consider how these meanings additionally are produced in relation to the broader cultural contexts. The local setting is always related to broader cultural norms, whether they are followed, contradicted or ignored. Consequently, it is important to simultaneously be attentive to how people's actions are agentic and how they are structured by other actions. As such, power relations are a precondition for our ways of being; individuals cannot exist outside them. Power relations in this way are productive, positive and creative rather than just repressive, negative and exclusive, and not only make us submit to certain norms for behaviour, but are productive in that they make realities, truths, objects and subjects (Foucault 1982/2002; Öhman 2010).

Power mechanisms motivate individuals and collectives to act in line with what is regarded as being generally good and right, rather than by requiring obedience, with threat of punishment, or by regulating and monitoring. This is a form of governance, which is characterised by the establishment of a relationship between prescribed actions and the individual's own 
responsibility to act in line with these actions in a specific context - a relationship between being governed and governing oneself (Foucault 1978/1991; Rose 1999). The relationship between governance and self-governance provides a way to think about which student subjectivities are made possible and desirable within a specific classroom context in relation to a specific subject matter. In particular, the concept of self-governance moves the focus from teachers' governance as unilateral to acknowledging the function of students' self-regulation. Further, it brings to the fore how a teacher's teaching repertoire may include such appeals to students' self-governance (Öhman 2010; Östman et al. 2015).

\section{Approaches to Studying Power Aspects in Science Classrooms}

In the following, we present a review of research of classroom studies that either implicitly or explicitly investigates the working of power within science education. We firstly consider literature that could be said to implicitly approach issues of power-through the study of communication structures - before moving on to literature that explicitly names power as the issue under investigation.

Mortimer and Scott (2003) investigated various forms and functions of discursive interactions and developed a framework for characterising different communicative approaches, for example as instances of dialogic and authoritative discourse. The communication forms in the science classroom are often found to be authoritative, where attention is focused only on one point of view, which may be inconsistent with students' own modes of communication. Learning in science lessons has been found to often privilege the memorisation of facts, rather than developing students' own capabilities to engage in meaningful scientific discourse (Crawford 2000; Jiménez-Aleixandre et al. 2000; Lemke 1990). Emdin (2011) points to the importance of support, especially for disadvantaged students' modes of communication, in order for them to truly participate in science talk in the classroom. Scott et al. (2006) show how both the dialogic and the authoritative pattern of interaction are necessary in order for students to engage in meaningful understanding of scientific conceptual knowledge and that the tension between the approaches is an inevitable characteristic of meaning-making in science. Further, they show that teachers may not be aware of how they constrain dialogue thereby limiting the amount of participation by students (Scott et al. 2006).

The central role of the teacher and how he or she establishes their communicative approach and the interaction patterns that occur during classroom discussions is well investigated. For example, Puntambekar et al. (2007) conducted a comparative study of two technologysupported inquiry curriculum classrooms, in which they showed how differences in teaching approaches led to very different classroom cultures and also affected the learning outcomes. They pointed out that the teacher plays a critical role in establishing the classroom culture.

In the same vein, Pimentel and McNiell (2013) investigated talk in whole class discussions in a secondary science classroom and found that the students' answers to questions were often very short and did not include reasoning unless this was specifically asked for. The teachers' actions in the classroom seemed to reinforce this participation pattern, for example, by rarely probing students' knowledge or directing questions back to the students. Teaching then ended up using an authoritative approach, even though the teachers' beliefs were that this was not an ideal manner of teaching. Many factors were given as explanations for this, for example, teachers' own knowledge and ability, students' lack of experience, content knowledge and motivation. Another factor was time; if students were not encouraged to speak or make explanations of their own, and instead priority was given to being correct, then content 
coverage might be increased, but it could also discourage students from sharing their thinking in discussions.

However, students' participation in classroom discussions is complex and does not necessarily follow the teacher's efforts to direct the taught content. Candela (1998) showed that the students may also make use of the discursive resources available for teachers and in this way exercise power. The ways in which students influenced the teacher's discussion structure were by refusing to participate in the discussion, defending their own explanations, evaluating teacher and student explanations, questioning the teacher's or other students' explanations, or by initiating other topics for discussion. Teachers could plan for activity task structure, initiate discussions and ask questions, but could not control how students responded. This highlights the matter of reciprocity in teaching-and-learning situations. In that the students act upon the teacher's actions by resisting, passively or actively engaging in class or acting their own initiative, they are co-constituters of the situation.

With a specific focus on how questions are associated with power dynamics, Reinsvold and Cochran's (2012) study of a third-grade science classroom showed that teacher talk was twice as frequent as student talk and that students asked few questions. The classroom discourse was thereby controlled by the teacher who employed traditional power strategies in teaching, despite the inquiry-based curriculum. While situated in the science classroom, the study does not problematise the subject-matter of science beyond whether an utterance is dealing with science subject-matter or not. In a later article, Cochran et al. (2017) point out that an effective classroom is one where students are empowered to engage with subject matter. They identify "Subject Matter Power" as one of five categories where an individual may use the discipline as an authority of knowledge. Also taking as their departure inquiry-based science teaching which can be claimed to diverge from traditional classroom culture, Donnelly et al. (2014) investigated mechanisms of power either as direct (e.g. surveillance) and indirect (e.g. ownership of ideas). They showed how classroom discourse constructs or maintains power relations that either support or prevent inquiry-based approaches. They found that teachers' questions often asked for procedural matters, rather than asking for how the students had understood the teaching content. They found that traditional power relations between teachers and students were maintained in both direct and indirect ways, which is in accordance with Reinsvold and Cochran's (2012) results.

Cornelius and Herrenkohl (2004) aimed to analyse particular participant structures and how these structures support, enable and incite scientific thinking. They showed how having ownership of ideas shifted power from the teacher to the students and also that it narrowed the distance between the student and the scientific concepts, which made the students feel that they were creators of their own ideas. To make students become spokespersons for different scientific theories allowed them to have and voice their own opinions on the issue at hand.

Our overview of research about how power operates in science classrooms has shown that issues concerning the disciplinary content are considered to a varying degree, but often there is a greater emphasis on general participant structure and interaction than on disciplinary-specific knowledge, values and norms. Even though this research is grounded in a variety of different theoretical approaches, a common trait of the studies is that the analyses start from the power relations or interaction in the classroom. Consequently, while set in science classrooms, what participating in a discipline-specific discourse consists of is to some extent taken for granted and the construction of school science as such is not problematised substantially. This calls for research approaches that consider knowledge and power as interrelated. Within science education, Danielsson et al. (2018) and Östman et al. (2015) have employed such approaches 
to investigate the interrelatedness between knowledge and power. We are herein drawing on this research to further develop an approach to be used on a different empirical material.

We approach the reciprocity of power relations and disciplinary-specific knowledge, values and norms by taking a knowledge-based framework as our starting point. The purpose is to explore and contrast different approaches to how power operates in the practice of physics teaching. Teaching in three different classrooms is analysed in order to facilitate the identification of differences and/or similarities in terms of how knowledge and power are staged and how governance is acted out. This is done by investigating how actions contribute to produce knowledge in classroom situations, through the research questions:

- What is privileged as relevant knowledge in the different physics classrooms?

- How is the privileging of knowledge done in the process of teaching in the different physics classrooms? That is as follows: What are the possibilities and limitations of this line of action; which actions become desirable or undesirable in the teachers' transactions with the students in the different classrooms?

\section{Context of Investigation and Analytical Process}

The study is framed by a case study approach, carried out in the form of small scale ethnographies of three physics classrooms, followed by cross-case analyses. Three different physics classrooms from lower secondary schools in Y8 and Y9, respectively (13-15-year-old students) were each followed during one whole teaching unit during the academic year 2014/2015. The data collection includes video and audio recordings, observations, field notes, informal conversations with teachers and photographs of classroom settings and artefacts. One or two researchers were present in the documentation of each lesson. When considering this material as a whole, we focus on the content-oriented aspects and in particular, how knowledge and power are simultaneously constituted.

The selection of participating classes aimed to have the possibility to reflect a diversity of different approaches to the teaching of physics, including both how teachers structure the activities in the classroom and opportunities for students' participation. The three schools are differently situated regarding geographical, social, economic and cultural school admission profiles. It is worth noting that it is not our purpose to use the background data to find 'reasons' behind or beyond what is actually said and done in class or explain why actions in the different classrooms happen as they do. Nevertheless, a description of each school ${ }^{1}$ is useful to shed light on the situations.

The first class in our sample is a year 9 class which attends the 'City School', located in a large Swedish city. The students are consistently high performing, and their merit points are well above the national average. Most of the students in the City School have parents with post-secondary education, and most students have a Swedish background. In the particular class we followed, $1 \mathrm{~h}$ a week is devoted to physics education. We have documented the work in the class during a teaching unit covering six lessons. The subject area is about different energy sources and the production of electricity.

\footnotetext{
${ }^{1}$ The following paragraphs are based on statistics on school results and student composition retrieved from the National Agency of Education's website SIRIS, a website that collects information about school quality and results (Skolverket 2017). Approximate indications are used in order not to facilitate recognition.
} 
The second class is a year 8 class which attends the 'Rural School', situated in the centre of a former industrial community. The students in this school are generally not high performing, with merit points significantly lower than the national average. Few of the students' parents have post-secondary education, and most students have a Swedish background. In this school, we have documented a teaching unit of six 65 -min lessons over 3 weeks concerning sound. In the unit different properties of sound and concepts to describe this, the construction of loudspeakers and a discussion about hearing are addressed.

The third class is a year 8 attending the 'Suburban School', a school located on the outskirts of a large city. Students in this school achieve significantly lower merit points than the national average. Among the parents of the students in this school, 3/5 have their highest level of education at secondary level, and 2/5 have post-secondary education. Around 2/5 of the students in the school are first- or second-generation immigrants. The language of instruction was nevertheless Swedish, and the absolute majority of students in this class were fluent in Swedish. The teaching unit at this school also concerned sound, and the class was followed during 11 lessons of varied lengths (45, 60 and $70 \mathrm{~min})$, over 4 weeks. The unit addressed properties of sound as well as the ear and hearing.

Each class is taught by a teacher who is recognised by independent sources as a 'good' teacher (such as having the career position of 'Excellent Teacher'). The three teachers are all experienced in teaching ( $>15$ years in the profession) and are well established at their respective schools. To be experienced matters in the way that teachers (and students too) act and respond in the situation related to their habits (Dewey 1922/83). To be experienced entails a teacher having lived through a multitude of situations, both similar to and different from the ones experienced in this sample. That we humans act in accordance with our habits accounts for our predisposition to draw upon modes of response to situations that arise within a teaching situation (Nelsen 2015).

The analysis applied the analytical facets of our research questions. The focus of the analysis is on how actions contribute to produce relevant knowledge in classroom situations, in other words, the content-oriented aspects of teaching. 'Teaching' is regarded as those actions by the teacher that have a guiding function for students, considering what counts as valid knowledge and skills and the proper ways of making knowledge within the situated practice (cf. Lidar et al. 2006). This is analytically approached through considering what is paid attention to as relevant knowledge in the different classrooms. We analyse teaching using the concepts of governance/self-governance as, in a methodological sense, governance means that a person's or several people's actions contribute to their own or other people's actions becoming reoriented, corrected or intensified in a specific direction. In this way, the governance forms included in different teaching practices indicate the desirable way of acting and how students explicitly and implicitly are encouraged to, and do, adhere to this. As a consequence of this, we analyse how teaching communicates possible ways of perceiving oneself in relation to the activity at hand.

The analysis set up to identify what actions are construed as relevant in physics classroom situations by both teacher and students and how students are willing to act in alignment with what appears as desirable (or not desirable) in the situation. In doing so, our analytical unit is 'action-upon-action', but we are also mindful that these actions take place in broader cultural settings. Carlone et al. (2011) point to the value of using a meso-level timescale in education research, since focusing too much on either sociohistorical or event-level emergence of cultural models may ignore the role played by actions habitually developed in a practice. Hence, our analytical process includes a continual 'zooming out' towards the empirical data as a whole 
and a 'zooming in' on specific sequences. This is also reflected in the reporting of the findings, and as such the findings integrate more descriptive sections with both analyses of individual transcripts and analyses of longer events. Subsequently, a smaller number of sequences (or excerpts thereof) that were particularly well suited to illustrate the co-constitution of knowledge and power were chosen for presentation, along with descriptions of events, aiming both to show the prevailing discourse and disruptions thereof.

As such we do not focus on how the participation of individual students unfolds, instead the students' collective participation is analysed. However, in moment-to-moment analysis, the sequence under scrutiny is always considered in its context and we also consider how the analytical facets can illuminate the surrounding context of a chosen sequence. Thus, in the reporting of the findings, we present transcripts of excerpts and the interpretation thereof framed by an ethnographically inspired narrative, albeit focused on how knowledge and power operate in the classrooms under investigation. Consequently, the analysis of each classroom moves between the micro-level of moment-to-moment interactions and the meso-level of the teaching unit and to some extent the macro-level of the community the school is situated in. Given the different levels, we have strived to provide suitably thick descriptions to enable the reader to trace the analysis back to the empirical data. The confirmability of the study is also ensured by continuous discussions of tentative analyses and conclusions among the authors.

The empirical material used in this article has been collected in accordance with the principles of informed consent, including consent from the students' guardians, given that the students are all below the age of 15 years. The students and their guardians were all given information about the research project and were asked to consent to video recording of classroom activity. All names used in the paper are pseudonyms, and the descriptions of the schools are deliberately vague so as not to facilitate recognition and to preserve the participants' confidentiality.

\section{Results}

\section{The City School}

The overall impression from this class was that as a whole the students were very academically capable, and many of the students participated in the whole class discussions and showed an interest in physics, in relation to the topic being taught and beyond.

The first lesson of the teaching unit concerning energy sources and the production of electricity begun with the teacher describing what they were going to do during the whole unit, including outlining what parts of the physics national curriculum the unit corresponded to. The bulk of the unit was carried out in the form of a group project, where the groups were assigned one type of renewable or non-renewable energy source, such as nuclear power, hydropower, fossil fuels or solar energy, to present orally to the rest of the class. In the final lesson, each student was allocated another source of energy than their project type, and a debate for or against this was carried out. The introduction also clearly signposted the teacher's expectations of the students and the type of objectives that was to be addressed during this unit, but not only did the introduction serve as instruction for how the work was planned. By repeatedly stressing an expectation that the students should be active, the teacher also implicitly communicated that this was not how things were usually done within their physics teaching: 


\section{Excerpt 1}

TEACHER: Then it is very very important that you are active, that you really take notes and study because we will have a final debate, and during that debate you will need to have an opinion, so if $\mathrm{NN}^{2}$ has now been working with nuclear power, for example, in group work, then you will not get nuclear in the debate, but you will get something else, you might get wind power, so it is important that you listen to your friends when wind power is being discussed as you won't know during the talks what you will get in the debate at the end, so you have to be a little bit active with every [talk], and then you will be either pro or against, $[\ldots]$

The governance form thus indicated that the desirable way of acting was an active way. Nevertheless, despite the repeated and very explicit calls for student activity, during the first lesson the student participation was largely confined to listening and answering questions from the teacher. By setting up the debate in such a way that the students were to debate about a different source of energy than the one they had researched, the teacher introduced a measure of control that encouraged the students to self-govern; that is, to be an active student during their classmates' presentations. The teacher also created an accountability set-up between the different student groups.

Before the group project started, the teacher provided an introduction to the nuclear reactor, which connected to the previous teaching unit which addressed atomic and nuclear physics. This teaching sequence served to show how teaching content was commonly distributed in this classroom. The teacher drove the classroom conversation, but invited students to contribute by posing questions that typically demand short, factual answers:

\section{Excerpt 2}

TEACHER: [...] What happens here inside the reactor then? Well, the nuclear reaction is in full swing. It forms a lot of heat, energy. What does it do then NN?

STUDENT 1: It heats the water so it converts, it condenses.

TEACHER: Exactly, it doesn't condense but it evaporates, yes it evaporates, then, right, it comes here then it condenses but it evaporates here, and then we get water vapour, which is led away in this bend and then it comes down to this point and what happens then NN?

STUDENT 2: So the steam drives a turbine that creates kinetic energy and then I think it connects to a generator that generates an electric current.

TEACHER: Okay, but first, what is a turbine?

STUDENT 2: It's a thing that goes round.

TEACHER: Exactly, it's like a propeller, one can say that the steam makes it start spinning so we get a rotating movement, so it starts to turn round and round and there we then have a generator and it generates electrically transferable energy and how does it do that, then? It is a bit tricky, we have not really talked so much about that, is there anyone who knows? NN?

STUDENT 3: Well, I'm just guessing, but when the turbine spins the generator like that there is something that makes the electrons move.

TEACHER: Yes, we have a rotating motion and then here in the generator there are permanent magnets located and then the magnet is spinning around

${ }^{2} \mathrm{NN}$ is a name of any student. 
The teacher's questions were of a generative character, directing attention towards scientific facts and expecting answers requiring a high level of knowledge. The answers to the questions cannot be drawn from what had already been said by the teacher, but required previous knowledge or experiences in order to be answered. Usually, the students responded in line with what is expected and got confirmation of this from the teacher. Confirmation was given even though the answer was not entirely correct, and the teacher continued to use the concepts the student brought in to the situation and set them right. Another student continued with a very dense explanation of how the steam drives the turbine with kinetic energy attached to a generator which gives electric energy. The teacher voiced a question to start unpacking this statement: What is a turbine? The answer was confirmed and further developed by the teacher. The explanation got to the point where further explanation of how a generator can transform kinetic energy into electric energy was needed. The teacher mentioned that this is something they have not addressed previously, but still asked if anybody knows. This was an indication of the high expectations on students' knowledge in physics. Even though Student 3 did not know the answer, he dared to take a guess. Student 3's answer did not further the explanation; nevertheless, the teacher confirmed his statement by picking up on the spinning movement and developed the explanation from there. The teacher, thus, continually acted upon the contributions of the students to bring out the scientific aspects of what had been said. This limited the possibilities for what could be talked about; it was the scientific concepts that the teacher took up and used. At the same time, it created opportunities for the students to take part in the scientific conversation, in that the students were invited to contribute with their knowledge, and their contributions could also be made scientific to suit the purpose the teacher was pursuing.

As the lesson moved on, the students' attention was continually directed towards the scientific facts. As nuclear power is a topic which is potentially politically and morally loaded, the attention to 'pure science' became visible in several occasions in what was not said. In the presentation of the nuclear reactor, the conclusion was drawn that a large amount of water is needed as a coolant and that is why all nuclear plants are located near water. The teacher asked the students whether they knew where in Sweden nuclear power plants are located geographically, and then continued to mention other (in)famous nuclear plants such as Fukushima and Three Mile Island with the only reference that they are located close to water. Nothing was mentioned of the fact that they are sites known for major nuclear meltdowns. The discussion was instead led back to water as a coolant, and that it is important that the water in the cooling system is separated from the water that drives the turbine, so that we do not get radioactive emissions. Likewise, the discussion about final disposal of nuclear waste focused on what containers are to be used for the storage, thereby directing the students' attention to scientific progress being made regarding what containers are most appropriate. Students' participation in the scientific conversation was encouraged, but moral standpoints concerning nuclear power and the political consequences thereof were closed down, and it was striking how the teacher manoeuvred the students back to the scientific facts, and the students readily went along with the teacher's reconstruction of their utterances.

In the following three lessons, the students worked in smaller groups with the source of energy (e.g. hydropower or solar energy) that they had been assigned by the teacher, preparing a presentation to be given to the whole class. During the group work, the teacher moved between the groups, specifying what they ought to focus on in their presentations. Here, a tension between freedom and control was played out, in that students were required to make 
their own inquiry about their source of energy, but they were told by the teacher what to include (for example, which energy transfers are present). This structured the possibilities for the students to act; the teacher could have used his participation in the small group discussions as a means of surveillance, but when joining a group's discussion, the teacher almost immediately directed them towards a certain content and rarely took their previous discussion into consideration. In doing so, the teacher directed the students' attention to specific factual and procedural components, which could function as to generate suitable conclusions. At the same time, it was the group's own responsibility to divide the work that needed to be done among themselves and to keep to the deadline, and as the lesson sequence proceeded the teacher governance lessened and the responsibility to complete the presentation was handed over to the students, which required that the students self-govern. For example, the students were expected to assign themselves homework in case they would not be able to meet the deadline during lesson time. The students' presentations of their source of energy followed the outline of what the teacher had instructed them to include, which was the energy transfers involved and the pros and cons of various sources of energy.

\section{The Rural School}

Throughout the teaching unit, the teacher mixed short briefings with demonstrations, laboratory activities which followed instructions, dramatisations and students reading and answering written questions. Before each of the lessons started, the teacher had written a bulleted list containing five or six bullet points on the whiteboard with varied activities, describing what the lesson would include. The teacher referred to this list as the lessons progressed, which meant that there was transparency in the objectives of the teacher.

The overall impression of this classroom was that it was quite unruly and hard for the teacher to get the students to focus on the activities at hand. Many students in the class devoted a lot of time and attention to non-curricular activities. To exemplify, it took about 12 min before the teacher could start the first lesson, due to non-content-related classroom management issues. It was expressed in, for example, students arriving late, without proper equipment, which could be characterised as student resistance to the pressure to conform to school discipline. This was critical for the progress of the lessons, but the general expressions of anti-school culture are not what we have in focus. Instead the focus of the analysis is on actions in relation to the teaching of knowledge related to physics.

We will present two excerpts from a briefing during the second lesson to serve as examples of the classroom transactions. The second lesson started out by the teacher saying: 'I thought I would have a short briefing about what we are doing. Do you remember what we did last time?' Scattered answers could be heard in the room, but eventually the teacher reminded the class that they started the sound unit. They talked about some of the concepts (echo, frequency, Hertz) connected to the sound unit that were mentioned in the first lesson. The teacher encouraged everybody to find something to take notes on, which eventually all students did. The teacher instructed everybody to write a title ('Sound waves') and draw a tuning fork on the whiteboard, and then turned to the students:

Excerpt 3

TEACHER: Have you drawn a nice tuning fork in your books?

STUDENT 3: Does it have to be nice?

TEACHER: Oh, just draw a tuning fork. 
STUDENT 4: Should we draw that? [with reference to the picture on the whiteboard] TEACHER: Let's all draw this. It's a tuning fork. We had those the last time. You remember this tuning fork, when we hit it with something, it began to vibrate, it moved back and forth. Hey, guys, we have a tuning fork here [a call for attention to students who are talking about other things]. When we strike at it the fork begins to move back and forth. What happens to the molecules in the air then, do you remember that?

STUDENT 5: I don't remember.

TEACHER: No, but you had molecules here, and what happens there if it [the tuning fork] starts to move?

STUDENT 5: Then they start to move.

The question from the teacher ('What happens with the molecules in the air?' ) served to direct the students' attention towards the molecules in the air and what happens when the fork moves. A question ('No, but you had molecules here, and what happens there if it [the tuning fork] starts to move?') directed the students to come to the conclusion that the molecules are set into motion. The direction of governance was towards what was important to pay attention to in order to draw the conclusion that the teacher has set out, which was the molecules' role in making sound. During all the teacher briefings, the teacher expected the students to copy down the notes from the board. The means the teacher used in order to involve the students were mainly of a controlling character, as in the excerpt above, when the focus was on whether the students remembered from last time. Thus, the teaching was comprised of actions of control and surveillance, checking that the students had followed. In a situation of reciprocity in the expectations between the teacher and the students, it was not within the field of possibilities for students to make contributions of their own content-wise, if the students were to answer the question. The teacher's actions can be understood as acting upon the inattentiveness of several of the students in the class. By checking whether the students were following, the teacher had the chance to evaluate if and how it was possible to proceed with the lesson.

The teaching sequence about how sound travels was elaborated on some more using the concepts of compression and rarefaction, and the teacher continued the drawing:

\section{Excerpt 4}

TEACHER: [...]Then there is some rarefaction and then there are fewer air molecules here and then when it vibrates back and forth there start to be constant compressions and rarefactions over the molecules in the air. I will try to draw an area where many particles are compressed, oops, so... [draws small "8"-shaped figures/molecules]

STUDENT 6: I'm not going to draw that.

STUDENT 7: Me neither.

TEACHER: These are the small particles that the air is made up from. If you want to keep it simple, you can just draw a dot instead. Just so you show that there are areas that are compressed and areas that are rarefacted, areas that are compressed, that it goes back and forth and it is in that manner that sound is propagated. We will write some things underneath. We'll write that there are compressions and rarefactions...

STUDENT 6: Do we have to draw all the molecular crap?

TEACHER: You can simplify it by just drawing dots if you like. I wanted to be clear to show ...

The picture on the whiteboard included a lot of detail, and some of the students said they refused to draw everything. The students were acting in resistance to the form of 
institutionalisation, where copying notes off the whiteboard is an established activity. In response, the teacher offered a reduction of the illustration: to draw the molecules as dots instead of $8 \mathrm{~s}$, a simpler way of drawing. This action opened up possibilities for the students who refused to draw to still follow the instruction without having to give up their say. To follow the instruction was construed as the desirable way to act in this situation and could function to keep students engaged in classroom work. The reduction still kept the illustrational value of the figure that the molecules/dots are more or less dense in the air. In addition, there is a value in physics to know how to reduce information in a relevant manner. The figure was subsequently additionally transformed to a wave diagram, and the teacher introduced crest, trough, frequency and talked about sounds with different pitch. The teacher asked some questions in the form of comprehension questions, to ensure that the students were following. Apart from this, student participation during the whole sequence was limited to pointing out that the teacher mispronounced a physics term on one occasion and that there was unclear writing on the whiteboard on another occasion.

The participant pattern was similar in the following lessons in the teaching unit. The teacher assigned the students' tasks to do, whether whole class briefings, reading a text and answering questions or building a loudspeaker from a given instruction. None of these activities opened up for the students to contribute to the progression of the teaching content. The teaching approach in this classroom was characterised by control and surveillance. That several of the students (but far from all) were not acting in a way that appears to be desirable in a school situation created a situation where the possibilities for the teacher to let students govern their own work was limited.

One occasion that stood out in the material from the Rural School was a sequence with a hearing test where the students were to identify which sound had the highest frequency, which was decided by a show of hands. This was followed by a test of the students' individual hearing range. The teacher played higher and higher pitched sounds from her computer and the students had to keep their hands raised as long as they could still hear the sound. This section of the lesson captured the students' attention, and the classroom was entirely quiet for the first time during the lesson. Here, the students' own experiences of hearing were made relevant in the conduct of the lesson. In this activity, the students had the freedom to govern the direction of actions, which made the test evolve into an activity similar to a competition. The rules for participating in the competition were negotiated, and the students who could hear the highest pitched sound appeared as the winners.

\section{The Suburban School}

Excerpts from the introductory lesson will serve as examples of the transactions between teacher and students in relation to the subject content. The teacher started with surveying the students' previous knowledge and experiences regarding sound with the question 'First, I'd like to know what you already know about sound, what is sound, what do you think about it?' The students answered this question with experiences of sound as vibrations, ears and music. The teacher noted all of this on the whiteboard in front of the students. By doing this, the teacher confirmed that the suggestions presented were valid in a physics teaching context. One student suggested that sound exists everywhere. This suggestion was not immediately accepted by the teacher. As a response to this, the suggestion that sound does not exist in space came up from another student. By questions that directed towards a discernment of the specific qualities that conditions the propagation of sound in space, namely that there needs to be some sort of 
particles, like atoms and molecules, they came to a joint conclusion that 'vacuum does not propagate sound'. With this line of action, the teacher allowed for the students to introduce the new content in a manner that can be described as letting the students take the lead. This is an illustration of such an instance where students made suggestions about what they knew about sound:

\section{Excerpt 5}

STUDENT 8: Echo

TEACHER: The sound can bounce, how?

STUDENT 8: When a place is empty, then, I don't know how to explain it...

STUDENT 9: If you are in a large empty place, then the sound comes back.

TEACHER: Precisely, then the sound bounces off the walls and comes back.

STUDENT 8: Then you can hear yourself.

TEACHER: It bounces now as well but now there is so much stuff that gets in the way as it is furnished in here, but in a very empty space, by a large mountain or an empty room or have you been in a tunnel sometime? There you almost can't help but shout "hello", when you go over to [nearby district] for example ... right, there it echoes.

STUDENT 8: Yeah, yeah, hoouw!

TEACHER: What more do you know about sound? You know lots of things already.

Should we write this down, echo that bounces, what else do we know?

One student brought in echo as a concept connected to the area. Through the teacher's answer, a relation was construed between echo, sound and bouncing. This can be understood as the teacher 'scaffolding' students' learning of the term 'echo', via the non-technical word 'bounce' to ensure that the students could move with the teacher in the learning process. The relation between 'bounce' and 'echo' gave 'echo' a definition, and the student's answer was confirmed as valid and also further elaborated on.

Following this, the teacher expanded the explanation by saying that sound bounces off the walls and comes back. Later on, the teacher connected the phenomenon of echo to a subway at a nearby location, where it could be presumed that many of the students have been. That students did follow the teacher in the learning process was evident when a student responded with the words 'Yeah, yeah, hoouw!." By exemplifying where echo can be experienced, the teacher offered an opportunity for the students to connect the physics content to their everyday experiences. This teacher responded to the students' contributions by intensifying them via repeating and elaborating their suggestions, a way of teaching that was repeatedly occurring in this classroom. Throughout the lesson, the students were expected to contribute with everyday experiences as well as factual knowledge. Consequently, it was the students that brought new content to the fore.

Meanwhile, the teacher also delineated what was possible to bring to the fore by not accepting all suggestions, and directing attention towards what was important to acknowledge. In the example mentioned above, delineation was made by specifying in what conditions sound can propagate. Stronger demarcations of the limits of physics teaching were also made:

\section{Excerpt 6}

STUDENT 10: Sounds can affect our emotions like in movies.

\section{TEACHER: Mmm.}

STUDENT 10: If there's happy music in a horror movie, then we don't get what happens. 
TEACHER: Exactly, the movie makers use sound to enhance the experience. When there is something exciting and scary there are scary sounds. If they started to play a little happy tune then it wouldn't be as dangerous, not as scary. Now we are talking about sound in terms of how we talk to each other and understand each other very well and how we communicate. When we talk about physics it's not so much about what we perceive and so on, atmosphere and that whole bit. We will talk about what sound actually is, the first word we got it that it is vibrations, that's where we will begin.

In this excerpt, one student related sound to emotions. The teacher confirmed that it correct that sound can be used to create a specific mood, but stressed that this is not what sound is in the context of physics. The wording 'what sound actually is' implied what is relevant to talk about in this context. The reference to sound as vibrations was a direction to what is important to address in the physics classroom. As this pointed to the specific knowledge requirements within this content area, it was adelineation towards the disciplinary knowledge of physics. Delineation of what counts as physics was also made when they come to talk about animals that use sound for communication, for example bats, whales and dolphins. They continued talking about which animals are mammals, but then the teacher firmly stated: 'But that belongs to another subject'. The teacher then continued the lesson by presenting the curriculum goals of the teaching unit and discussed some concrete examples of knowledge that the students were expected to learn during the unit. In doing this, delineations were also made by the students in an instance where the teacher mentioned that to talk about the ear was one of the goals, a student response was 'We have studied the body already', which the teacher responds to by clarifying that the focus now is on the parts of the ear and how sound waves are transported, which also serves as a direction towards what counts as physics.

The students were instructed to copy the text off the whiteboard, where the goals were written down, and the teacher explained and illustrated what it was she was writing. The illustrations were made for example by changing the loudness and pitch in her voice, and she mentioned that these are hard concepts since they are easily confused in everyday language. The words she used were 'everyday language can cause problems'. Despite her continual emphasis on connecting the physics content to students' everyday experiences, this demonstrated that the students cannot expect that physics always can be easily equated with everyday life.

Lessons five to nine in the teaching unit were devoted to students' independent investigations of sound, both by reading/discussing and doing laboratory work. The students were given the task of covering the whole unit in the textbook (about 20 pages), and then making plans for conducting and reporting from their own investigations of phenomena related to sound. The task included considerable freedom for the students to investigate whatever they wanted. The freedom of the task proved to be difficult for the students to make use of. The teacher hinted that there was a two-page spread in the textbook with instructions for simple experiments, and this was what every student used. The expectations for the reports were not clearly articulated, but most of the students in the class decided to document their work by making a film about it on their iPad. To work with iPads was a way of work that they were accustomed to and it was a significant element in teaching in all school subjects in this school. In theory, the possibilities to engage with the physics content of the task was there, but without directions towards the way of working with the physics content, the focus in many of the student groups' work came to concern the film production. The students' own experiences and their investigations were not sufficient to govern their work in a direction that included exploring the physics content. In 
the last two lessons, the students showed their reports to the class. The physics content in all films was, with one exception, limited to showing the procedure of the performed experiment without attempts to explanation or draw conclusions about what happened in the experiment. The teacher reinforced the interpretation of the task as focused on film production by commenting on the aesthetic qualities of the films rather than the physics content. This had a pedagogical function in not publicly criticising students' performances, but the consequence was that what became privileged as relevant physics knowledge in this situation was very different from the content in the teacher's own briefing.

\section{Contrasting the Classrooms: a Discussion of Similarities and Differences}

At first glance, the teaching in all three of the studied classrooms appeared to adhere closely to a rather traditional interpretation of a physics curriculum. They all had a strong focus on factual science knowledge and a distinct progression through the curriculum. This corresponds well with research that has found science lessons to often privilege the memorisation of facts, rather than developing students' own capability to engage in meaningful scientific discourse (Crawford 2000; Jiménez-Aleixandre et al. 2000; Lemke 1990). But, with a closer look, and with different illustrations to contrast with, it is possible to nuance this picture.

In both the City School and the Rural School, the direction of teacher governance was towards scientific facts. However, while the direction of teacher governance was similar in the two classrooms, the expected student actions were quite different, as were the staging of selfgovernance. In the City School, this governing became particularly explicit in that the teacher did not act upon the potential for involvement of moral and political elements in either the students' contributions or the lesson content as such. In the Rural School, the direction towards scientific facts was accomplished by the teacher reinterpreting the students' resistance to adhere to her instructions in terms of a productive reduction of the science content. The teacher was engaged in a continuous surveillance of whether the students were paying attention during the briefings and if they copied the notes off the whiteboard. Student participation, thus, was confined to keeping up with what the teacher (just recently or the lesson before) had presented or assigned to them. This meant that the students were not expected to contribute with new aspects of physics content, beyond what had already been brought to the fore by the teacher. The ownership of the physics knowledge was thus firmly situated with the teacher.

The teacher-student transactions in the City School were of a similar character, in that the teacher brought attention to the scientific fact components of students' answers and guided their project work to specific areas of interest. The major difference, though, was that here the teacher was expecting students to give answers involving science knowledge he had not yet presented. There was a mutual expectation that the teacher would ask relevant questions and that the students would then give relevant answers and even though the questions were hard, guesses as well as demonstrations of knowledge received positive confirmation. Student involvement in this classroom became limited to providing relevant answers to the teacher's questions. If needed, these answers were then reconstructed by the teacher to fit his objectives.

In the Suburban School, the content area was broadly defined by the teacher, but the students were invited to contribute their own knowledge and experiences related to this area. In contrast to the two other schools, it was the students that drove the introduction of new content and teacher governance was manifested in terms of an explicit delineation of whether the aspects introduced by the students were relevant to physics or not. 
In both the City School and the Suburban School, the students were constituted as subjects that can partake in a physics conversation, and, within a field of possibilities, self-govern in terms of bringing relevant knowledge to the fore without being coerced to do so. In the City School, students were in general clearly socialised into a willingness to follow the teacher's objectives, including accepting the challenges to extend the science conversation beyond what the teacher had introduced. In both classrooms, the students were also expected to self-govern in relation to the completion of the group task they have been set, to take responsibility for their own learning. But, even though the suburban students were presented with a field of possibilities, they can be said to self-govern in relation to school science expectations by exclusively choosing to perform experiments from their textbook. In the Rural School, the governance was largely staged in terms of students not intervening in the physics knowledge as defined by the teacher, and expectations on self-governance were very limited.

\section{Discussion and Conclusions}

Based on the premise that there are different purposes for learning science in school, this study set out to explore how the content and actions in three different physics classrooms privileged particular ways of acting and being. This was done in order to generate a better understanding of why physics teaching in lower secondary school unfolds as it does. Actions construe different possibilities and limitations for students' learning, and different actions appear as desirable or undesirable in teachers' transactions with students in different classrooms. Central to the enterprise of compulsory schooling must be a concern with what kind of people we want our students to become and how the practices we provide contribute to this formation.

In the City School, the privileging of knowledge was directed towards introducing the students to the basic knowledge and skills of the scientific discipline (Roberts 1982, 2007). Even though the working unit finished up with a debate, this was not something that the students got to practice for, and the teacher leading the debate pointed to the importance of only using scientific arguments in the debate, which would be called an instance of authoritative approach in Mortimer and Scott's (2003) framework. The mutual teacher-student expectations of what a successful student is in this classroom, and thereby the desirable student action, is to be someone who can answer correctly when asked scientific questions by the teacher.

Similarly, in the Rural School, introducing the students to knowledge and skills of the scientific discipline was the privileged knowledge in teaching, even though there were instances, like in the latter part of the teaching unit, where students' experiences of hearing were brought to the fore, which entails a possibility to acknowledge the applicability of physics in everyday life (Roberts 1982, 2007). As Cornelius and Herrenkohl (2004) showed, student ownership of ideas could narrow the distance between the student and the scientific concepts. A possible consequence by a strong teacher ownership of the physics content is that this subject area is not open for contributions from the students and, thus, the students will be constructed as outsiders in relation to physics. Nevertheless, the students in the City School class were on a general level attentive, engaged and showed an interest in physics, while the students in the Rural School showed quite the opposite.

Pimentel and McNiell (2013) found that teachers' actions in the classroom in many instances seemed to reinforce a student participation pattern of giving shorthand answers with no reasoning included. We want to enhance this conclusion by emphasising that the 
teacher's actions too are a construct of actions upon the students' actions. In the Rural School, there are several instances where some of the students exhibit resistance in the teaching situation. Throughout such a teaching sequence, the teacher then needs to act upon the acts of resistance, which for instance result in multiple repetitions, (maybe) over-explicitness and a reduction of the teaching content, which in turn acts upon all students in class. Even though there are just a few students who actively act in a resistant manner, the consequences of resistance, such as reduction of content are presented to all students. This makes a strong contrast to the situation in the City School, where the students' willingness to respond to calls from the teacher to participate in classroom discussions, even though it may be just a guess, construe totally different fields of possibilities for the teachers. In the classroom transactions, the teacher in the City School was construed as a skilled, appreciated, knowledgeable teacher, while the teacher in the Rural School was constructed as not knowledgeable, for example by the students questioning her pedagogical content choices and the way she taught physics. Candela (1998) states that students may exercise power in that the teacher cannot control how the students respond to task structure, discussions and questions. However, as shown in our analysis, this power enactment by the students is not just something taking place in the individual interactions, but is constituted as an interactional pattern in the classroom.

In the Suburban School, science was staged as something that can be connected to coping with everyday activities and possible problems in life (Roberts 2007). The students were invited to contribute with their own experiences as well as factual knowledge. In doing so, it was the students who brought new content to the fore. The teacher responded to the students' contributions by intensifying, repeating and elaborating, as well as delineating what was to be included as physics. The desirable student action was thus to be able to contribute in scientific discussions and the teaching progresses content-wise as a sufficient number of students adhere to the teacher's calls to contribute, which can be understood as self-governance.

A central part of governmentality is the understanding that power processes and governance, through different discourses and forms of knowledge, produce and shape desirable subjects (Foucault 1978/1991; Rose 1999). The active and free subject is a prerequisite and the very essence of modern societies, especially in neo-liberalised societies. In order for neoliberal power processes to work, it is necessary that the free subjects transpose norms and ideals of their own free will. However, freedom also requires institutions and teachers who can shape freedom in the right direction and guide the autonomous individuals to choose 'right'. In an increasingly individualised society where people are expected to be active, reflective and make choices for their own personal good, the students in these three classrooms were offered very different conditions to practice and learn to take part in knowledge-making, connect physics content to their everyday life and exercise informed citizenship.

While the teaching approaches in the different schools in this study might not give rise to the inclusion of very different physics content, the consequences for potential student subjectivities are quite dissimilar. In other words, the content is similar in all classrooms, but the establishment of the content and who gets to participate differ. Calls for a more knowledge-based curriculum, that are often heard in the educational policy debate (e.g. Young 2013), do not consider this (Biesta 2014). Teaching and learning include so much more than core knowledge. From a policy perspective, it is not possible to change the conditions for education in more disadvantaged areas solely by prescribing 
more clearly what physics content to teach. Similarly, it is vital for teachers to direct their attention not only to which content is included or excluded, but also to who is invited to contribute to the progression of the development of content.

Acknowledgements This research was supported by the Swedish Research Council (grant dnr 2012-5472). We would like to thank the following colleagues for valuable contributions in the research process: Marie Öhman, Eva Silfver, Heather Mendick, Heather King, Louise Archer and John Airey. In addition, we would also like to thank the two anonymous reviewers for their constructive comments.

Open Access This article is distributed under the terms of the Creative Commons Attribution 4.0 International License (http://creativecommons.org/licenses/by/4.0/), which permits unrestricted use, distribution, and reproduction in any medium, provided you give appropriate credit to the original author(s) and the source, provide a link to the Creative Commons license, and indicate if changes were made.

\section{References}

Archer, L., DeWitt, J., Osborne, J., Dillon, J., Willis, B., \& Wong, B. (2012). Science aspirations, capital, and family habitus: How families shape children's engagement and identification with science. American Educational Research Journal, 49(5), 881-908. https://doi.org/10.3102/0002831211433290.

Archer, L., DeWitt, J., \& Osborne, J. (2015). Is science for us? Black students' and parents' views of science and science careers. Science Education, 99, 199-237. https://doi.org/10.1002/sce.21146.

Barker, D., \& Quennerstedt, M. (2016). Power and group work in physical education: a Foucauldian perspective. European Physical Education Review [Special Issue] 1-15. https://doi.org/10.1177/1356336X15620716.

Biesta, G. (2014). Pragmatising the curriculum: bringing knowledge back into the curriculum conversation, but via pragmatism. The Curriculum Journal, 25, 29-49. https://doi.org/10.1080/09585176.2013.874954.

Bøe, M. V., \& Henriksen, E. K. (2013). Love it or leave it: Norwegian students' motivations and expectations for postcompulsory physics. Science Education, 97(4), 550-573. https://doi.org/10.1002/sce.21068.

Candela, A. (1998). Students' power in classroom discourse. Linguistics and Education, 10, 139-163. https://doi. org/10.1016/S0898-5898(99)80107-7.

Carlone, H. B., Haun-Frank, J., \& Webb, A. (2011). Assessing equity beyond knowledge- and skills-based outcomes: a comparative ethnography of two fourth-grade reform-based science classrooms. Journal of Research in Science Teaching, 48, 459-485. https://doi.org/10.1002/tea.20413.

Cochran, K. F., Reinsvold, L. A., \& Hess, C. A. (2017). Giving students the power to engage with learning. Research in Science Education, 47, 1379-1401. https://doi.org/10.1007/s11165-016-9555-5.

Cornelius, L. L., \& Herrenkohl, L. R. (2004). Power in the classroom: how the classroom environment shapes students' relationships with each other and with concepts. Cognition and Instruction, 22, 467-498. https://doi.org/10.1207/s1532690Xci2204_4.

Crawford, T. (2000). Embracing the essence of inquiry: New roles for science teachers. Journal of Research in Science Teaching, 37, 916-937.

Danielsson, A., Berge, M. \& Lidar, M. (2018). Knowledge and power in the technology classroom: a framework for studying teachers and students in action. Cultural Studies in Science Education, 13, 163-184. https://doi. org/10.1007/s11422-016-9782-0

Dewey, J. (1922/1983). Human nature and conduct. In J. A. Boydston (Ed.), John Dewey: The Middle Works, Volume 14. Carbondale: Southern Illinois University Press.

Dewey, J., \& Bentley, A. F. (1949/1991). Knowing and the known. Boston: The Beacon Press.

Donnelly, D. F., McGarr, O., \& O'Reilly, J. (2014). Just be quiet and listen to exactly what he's saying': conceptualising power relations in inquiry-oriented classrooms. International Journal of Science Education, 36, 2029-2054. https://doi.org/10.1080/09500693.2014.889867.

Emdin, C. (2011). Dimensions of communication in urban science education: Interactions and transactions. Science Education, 95, 1-20. https://doi.org/10.1002/sce.20411.

Fensham, P. J. (1988). Familiar but different: some dilemmas and new directions in science education. In P. J. Fensham (Ed.), Development and dilemmas in science education (pp. 1-26). London: Falmer Press.

Foucault, M. (1977). Discipline and punish: the birth of the prison. New York: Pantheon Books.

Foucault, M. (1978/1991). Governmentality. In G. Burchell, C. Gordon, \& A. Miller (Eds.), The Foucault effect: studies in governmentality: with two lectures by and an interview with Michel Foucault (pp. 87-104). Chicago: The University of Chicago Press. 
Foucault, M. (1982/2002). The subject and power. In D. Faubion (Ed.), Essential works of Foucault 1954-1984. Volume 3, power (pp. 326-348). London: Penguin Books.

Francis, B., Archer, L., Moote, J., de Witt, J., \& Yeomans, L. (2016). Femininity, science and the denigration of the girly girl. British Journal of Sociology of Education, Online First. https://doi.org/10.1080 /01425692.2016.1253455.

Jiménez-Aleixandre, M. P., Rodríguez, A. B., \& Duschl, R. A. (2000). "Doing the lesson" or "doing science": Argument in high school genetics. Science Education, 84, 757-792.

Lemke, J. (1990). Talking science: Language, learning, and values. Norwood: Ablex.

Lidar, M., Lundqvist, E., \& Östman, L. (2006). Teaching and learning in the science classroom: The interplay between teachers' epistemological moves and students' practical epistemology. Science Education, 90, 148163. https://doi.org/10.1002/sce.20092

Mogensen, F., \& Schnack, K. (2010). The action competence approach and the "new" discourses of education for sustainable development, competence and quality criteria. Environmental Education Research, 16, 59-74. https://doi.org/10.1080/13504620903504032.

Mortimer, E. F., \& Scott, P. H. (2003). Meaning making in secondary science classrooms. Maidenhead: Open University Press.

Nelsen, P. J. (2015). Intelligent dispositions: Dewey, habits and inquiry in teacher education. Journal of Teacher Education, 6(1), 86-97. https://doi.org/10.1177/0022487114535267 .

Öhman, M. (2010). Analysing the direction of socialisation from a power perspective. Sport, Education and Society, 15, 393-409. https://doi.org/10.1080/13573322.2010.514735.

Östman, L. (1998). How companion meanings are expressed by science education discourse. In D. A. Roberts \& L. Östman (Eds.), Problems of meaning in science curriculum. New York: Teachers College Press.

Östman, L. \& Öhman, J. (2010). A transactional approach to learning. Paper presented at John Dewey Society, American Educational Research Association, Denver, USA. Retrived April 102016 from: https://www. researchgate.net/profile/Johan_Oehman/publication/267838157_A_Transactional_Approach_to_ Learning/links/54636a890cf2c0c-̄aec4b858.pdf.

Östman, L., Öhman, M., Lundqvist, E. \& Lidar, M. (2015). Teaching, learning and governance in science education and physical education: a comparative approach. Interchange, 46, 369-386. https://doi. org/10.1007/s10780-015-9268-0.

Pimentel, D. S., \& McNiell, K. (2013). Conducting talk in secondary science classrooms: Investigating instructional moves and teachers' beliefs. Science Education, 97, 367-394. https://doi.org/10.1002 /sce.21061.

Puntambekar, S., Stylianou, A., \& Goldstein, J. (2007). Comparing classroom enactments of an inquiry curriculum: lessons learned from two teachers. Journal of the Learning Sciences, 16, 81-130.

Quennerstedt, M. (2008). Studying the institutional dimension of meaning making: A way to analyze subject content in physical education. Journal of Teaching in Physical Education, 27, 434 444. https://doi. org/10.1123/jtpe.27.3.434.

Reinsvold, L. A., \& Cochran, K. F. (2012). Power dynamics and questioning in elementary science classrooms. Journal of Science Teacher Education, 23, 745-768. https://doi.org/10.1007/s10972-011-9235-2.

Roberts, D. A. (1982). Developing the concept of "curriculum emphases" in science education. Science Education, 66, 243-260. https://doi.org/10.1002/sce.3730660209.

Roberts, D. A. (2007). Scientific literacy/science literacy. In S. K. Abell \& N. G. Lederman (Eds.), Handbook of research on science education (pp. 729-780). Mahwah: Lawrence Erlbaum.

Rose, N. (1999). Powers of freedom. Reframing political thought. Cambridge: Cambridge University Press.

Scott, P. H., Mortimer, E. F., \& Aguiar, O. G. (2006). The tension between authoritative and dialogic discourse: a fundamental characteristic of meaning making interactions in high school science lessons. Science Education, 90, 605-631. https://doi.org/10.1002/sce.20131.

Skolverket (2017). SIRIS. Kvalitet och resultat i skolan. [SIRIS. Quality and results in schools]. Retrieved May 12, 2017, From http://www.siris.skolverket.se/.

Wertsch, J. V. (1991). Voices of the mind: a sociocultural approach to mediated action. Cambridge: Harvard University Press.

Young, M. (2013). Overcoming the crisis in curriculum theory: a knowledge-based approach. Journal of Curriculum Studies, 45, 101-118. https://doi.org/10.1080/00220272.2013.764505. 